Article

\title{
Education as Re-Embedding: Stroud Communiversity, Walking the Land and the Enduring Spell of the Sensuous
}

\author{
Molly Scott Cato * and Jan Myers \\ Cardiff Institute for Co-operative Studies, Cardiff School of Management, University of Wales \\ Institute, Cardiff (UWIC), Western Avenue, Cardiff CF5 2YB, Wales, UK; \\ E-Mail: jmyers@uwic.ac.uk
}

* Author to whom correspondence should be addressed; E-Mail: MScott-Cato@uwic.ac.uk.

Received: 3 November 2010; in revised form: 11 December 2010 / Accepted: 15 December 2010 / Published: 24 December 2010

\begin{abstract}
How we know, is at least as important as what we know: Before educationalists can begin to teach sustainability, we need to explore our own views of the world and how these are formed. The paper explores the ontological assumptions that underpin, usually implicitly, the pedagogical relationship and opens up the question of how people know each other and the world they share. Using understandings based in a phenomenological approach and guided by social constructionism, it suggests that the most appropriate pedagogical method for teaching sustainability is one based on situated learning and reflexive practice. To support its ontological questioning, the paper highlights two alternative culture's ways of understanding and recording the world: Those of the Inca who inhabited pre-Columbian Peru, which was based on the quipu system of knotted strings, and the complex social and religious system of the songlines of the original people of Australia. As an indication of the sorts of teaching experiences that an emancipatory and relational pedagogy might give rise to, the paper offers examples of two community learning experiences in the exemplar sustainable community of Stroud, Gloucestershire in the United Kingdom where the authors live.
\end{abstract}

Keywords: sustainability; re-embedding; phenomenology; songlines; experiential learning 
"I note as I work that how I am

Physically and Mentally has also

Moved, my mind stilled, my senses

Freed to Walk with the Land."

Anna Spurr. August 30th 2010

\section{Introduction}

How we know, is at least as important as what we know. Hence our approach to teaching needs to begin with a re-exploration of our own approach to knowing our world. As suggested by Simon cited by Giroux [1] 'any discussion of pedagogy must begin with a discussion of educational practice as a form of cultural politics, as a particular way in which a sense of identity, place, worth and, above all, value is informed by practices which organize knowledge and meaning'. As educationalists, we (the authors) draw on the ideas and influences of both Deleuze and Merleau-Ponty and it is necessary to frame our discussion with a very brief reference to why we bring these two thinkers together. However, we would refer readers to, for example, Lawlor [2-4] and Somers-Hall [5], for more in-depth deliberation of the convergence and divergence of the conceptual and methodological approaches of Deleuze and the early and later writings of Merleau-Ponty.

Most of the university curriculum, even in environmental science, is still conveyed only at the level of the mind and adheres to a Cartesian linear approach that suggests that 'thought and understanding is necessarily understood in terms of cause and effect' [6]. This has also helped to promote a preferred rational or scientific approach to learning and cognitive development, which Manley suggests negates other forms of understanding 'which were not founded in the thinking brain' [6]. These other forms of understanding are highlighted in discussions of mind-body distinctions, subjective-objective 'realities', knowledge as a product of programmed learning (science, education, theory) and knowledge as a process acquired through practice (experiential learning) [7]. Both Merleau-Ponty and Deleuze provide us with similar yet differing frames of reference to question the dominance of Cartesian dualist thinking so prominent in Western epistemology. In addition to Lawlor and Somers-Hall mentioned above, there are a number of writers that look at both the convergence and divergence of Merleau-Ponty's and Deleuze's ideas. For example, Manley [6] both points to 'subtleties of difference' and highlights points of contact between the two, through the influences of Bergson and Heidegger, while Morris [8] points to similarities in their treatment of 'difference'. From a philosophical point of view, we underpin our discussion with Deleuze's [9] suggestion that knowledge advances through a passionate commitment in relation to the physical world. We also explore Merleau-Ponty's [10] suggestion that the basis of perception is relationship, and especially how we might extend beyond inter-personal relationships to consider our connections with other species and inanimate aspects of the planet. In this paper, then, we seek to apply these theoretical musings to our more pragmatic understanding of how our way of knowing might limit the extent of what we can know and how we learn and teach.

Critical pedagogy needs to encourage critical reflection between theoretical aspects of learning and the praxis of everyday life. For those of us working in higher education institutions, while we may need to acquire the technicalities of practical teaching, we need also to seek how to question the 
assumption that acquisition of knowledge is only about programmed learning and education; that it is also in the understanding and transformation that comes from 'a sense of critique and possibility' [1]. For example, how might knowledge conveyed through an abstract system of writing differ from knowledge derived through a community of song, as is the case with the Aboriginal songlines? In this sense, we value different types of knowledge and routes to acquisition, which come through the functions and processes of intellectualizing (contextualizing, problematizing, reflexivity) rather than being the possession of 'the' intellectual, the tribe, the community. This is much less about knowledge per se (and the pursuit of the 'right knowledge' [11]) and more about knowledge in action - the meaning of knowing [12-14]; that is that 'meaning and knowledge are constructed and not 'found in things and events' [15].

The following sections of the paper expand on the ideas that knowledge is 'constructed through social practice' [16] and that there is 'interdependency of activity, meaning, cognition, learning and knowing' [17]. In the next section, we take, as our jumping-off point, a phenomenological and social constructionist approach to knowledge. Section 3 addresses the question of commitment and considers the importance of emotional response to the creation of our sense of reality. These philosophical considerations are then applied, in Section 4, to two knowledge systems that are in stark contrast to our own literary tradition: The songlines of Australia's original people, and the qhipu communication system of the ancient Inca civilization of Peru. In Section 5, we apply these theoretical explorations of knowledge formation to two educational settings from our own local environment: Stroud-a small market town in the UK-is an exemplar sustainable community and therefore offers opportunities to explore how shared learning might offer the possibility of re-embedding ourselves in our local environment. Stroud Communiversity and the Walking the Land artist group are two examples of deliberate attempts to develop this sort of learning experience. In conclusion, we ask how such experiences can be made available to students on more conventional business and management courses in U.K. higher education institutions.

\section{Knowing What We Know—and Creating New Ways of Knowing}

Gergen suggests that 'beliefs about knowledge...inform, justify and sustain our practices of education' and he describes two main strands used to differentiate views of knowledge: Exogenic and endogenic, both of which place emphasis on rational frameworks of understanding, but from differing perspectives [18]. In western intellectual culture we are pretty confident that we agree about the standards that we require before we are sure that we know something. As described by Feyerabend [19], these are based on rational reasoning around processes of evidence and logic to give us, as learners, proof of some objective existence or truth. This resonates with the exogenic basis of knowledge where the world is seen as objective and knowledge is acquired. This puts emphasis on specific subject curricula and techniques that favor information gathering and processing both from programmed education and from direct experience (taught classes, lectures, experiments).

While still rational, but less objective in its stance, the endogenic approach to knowledge emphasizes the internal reasoning and 'the human being's intrinsic capacities for insight, logic or conceptual development' where the 'mental world [is] self-evident' and where 'limits to learning may be traced to the developmental stage of the cognitive system' [18]. Yet, as Feyerabend contends, 
scientific thought 'is just one of the many ideologies that propel society... an intellectual discipline that can be examined and criticized by anyone who is interested...'[19]. Instead of trying different educational technologies to ascertain how we come to know and understand the objects and entities of our objective world and how best to transfer this knowledge from 'experts' to 'learners', we can shift focus and interest to how people relate, and build concepts of identity and being in the world, to see how we conceptualize and make sense of ourselves and our worlds. This brings to the fore the polyvocality - the multiple voices and plurality of worldviews that challenge our traditional western or European learning systems, as Stock describes:

First Nations people in western Canada see the forests of British Columbia as sacred spaces. People from a European background see them as resources to be 'used' or 'developed' even if for leisure. The giving of land back to First Nations people in Canada elicited the complaint that they do not 'do' anything with it. The idea that sometimes the point is to 'be' rather than to 'do' seems to have proved very hard to communicate [20].

It is likely that readers of this article are already convinced of the importance of taking a longer-term perspective on resource use, and would thus be sympathetic to the view as expressed by the First Nations people through the lens of a white, western woman researcher. Yet this is only the beginning of the lengthy process of understanding this wholly distinct worldview.

This nexus between differing world views and different knowledge and subsequent actions can both be an opportunity for new learning and an emergence of new knowledge systems. An example of the latter is demonstrated by Barnhardt in an article documenting the emergence of a new generation of indigenous researchers in Alaska [21] and by Ruwhiu and Cone in relation to kauapa Mäori research [22]. What is important here, is the unsettling of a previously privileged discourse, an historical and embedded discourse from a 'civilised' culture of pioneers, conquerors and colonialists, who on initially encountering First Nations and indigenous Peoples' way of life considered it inferior and yet now value their wisdom as contributing to a different understanding of life and collective reality. In the context of the sustainability crisis, this awareness of an alternative perspective acquires added salience. The 'pressure is on to share...wisdom' [23], given the economic and environmental crises that we face.

So in this context of multiple perspectives and global crises, how can we establish a confident approach to teaching that conveys something meaningful to students without unduly privileging a view of the world that must always, necessarily, be partial? Before moving on to consider the practicalities of this task, we need to consider the methodological approaches that can help us provide the scaffolding to a new and deliberate curriculum for sustainability in higher education.

As Abram suggests, the philosophical approach of thinkers such as Merleau-Ponty may be useful in establishing a shared basis for communication and understanding, but without the need to establish an objectively 'right' position. In this respect, 'striving for objectivity is thus understood, phenomenologically, as a striving to achieve greater consensus, greater agreement or consonance among a plurality of subjects, rather than as an attempt to avoid subjectivity altogether'; objective reality is thus a theoretical construction 'an unwarranted idealization of intersubjective experience' [24]. Perception, and the understanding it gives rise to, derive from relationship. As such, meaning is constructed at a local and immediate level where 'particular and individual experiences' are 
included 'in a pluralist discussion of multiple realities' [25]. This in turn gives focus to the learners' experiences and contextualized knowledge: historically marginalized views counter to the mainstream discourse of business education and developing management practice are given voice. This allows for more flexible, transformative and emancipatory practice.

Merleau-Ponty's writings on nature are pertinent here, when thinking about education and sustainability. Furthermore, Brook suggests that Evernden's bringing together of Merleau-Ponty's work and his own notion of people as 'fields of care' brings to the fore 'a realisation of our actual situation and a change in our response to the world' [26]. As already suggested, the unspoken assumption about the way we acquire knowledge we share with students is that there is a rational process whereby we are presented with a problem, we seek reliable (scientific?) evidence, weigh it rationally, and hence arrive at an objective and irrefutable conclusion, what Heidegger would refer to as 'calculative thinking' [27]. Even in areas that are less emotionally charged than the question of the survival of the human species, we would suggest that this is an idealized view that has little to do with the way people learn.

In many respects, our way of knowing the world, through a process of literary abstraction, may actually have impaired our ability to directly experience it, and hence to feel an affinity which may be the precursor to a sustainable stewardship approach. Before we were able to write, at least in the view of Abram, things were very different:

In the absence of formal writing systems, human communities come to know themselves primarily as they are reflected back by the animals and the animate landscapes with which they are directly engaged. This epistemological dependence is readily evidenced, on every continent, by the diverse modes of identification commonly categorized under the single term "totemism" [24].

The relationship between the human community and 'the environment', made up as it still is by a multiplicity of other animate and inanimate beings, was more direct before the spread of literacy, and in Abram's opinion this impacted significantly on what we perceived to be the real world we were inhabiting. The issue here is not to rely on theories and abstractions but to 'interpret nature from our own natural perspective within it' [28]; our physical, emotional and cognitive connections; our knowing what we know and being open and receptive to new emotions, new feelings, new thoughts, the new opportunities for sensemaking and making new meanings. Abram suggests that this is exactly what we do, through a process of reciprocal conditioning: 'The world and I reciprocate one another. The landscape as I directly experience it is hardly a determinate object; it is an ambiguous realm that responds to my emotions and calls forth feelings from me in turn' [24]. Likewise the distinction between subject and object dissolves 'as embodied habituations with the natural world increase ... slowly lead to the absorption of this larger organism into our bodies, and our bodies into it.' [29]. Rather than passively receiving external sensations, our perceptions as part of our experience suggest active engagement, creation and recreation (emergence) of self in relation with others (objects and people) and our environment (our 'situated' and 'social' learning). 


\section{Situating Learning for Sustainability}

As already suggested, in the western world, our confidence in the superiority of our way of knowing the world arises, we would contend, from its ability to manipulate physical systems with extreme precision and purpose; from what Val Plumwood calls the 'mastery of nature' [30]. And yet, the obverse of this mastery appears to be the restlessness and unsustainability that our way of knowing also gives rise to. We would further suggest that, at very least, we might consider other ways of knowing, if our intention is to learn and teach about sustainability. In this section we take forward our argument by considering how learning approaches and pedagogies might be designed to respond to these alternative ways of knowing. Here we find support in the writing of Deleuze and Guttari, whose work, since the late 1990s, has been gathering momentum in the field of education as a framework that 'enriches our understanding of such a complex open-ended process as learning... and the whole educational experience' [31].

As Cato and Hillier [32] point out, a guiding theme of Deleuze's work is the importance of a 'philosophy of difference': An emancipatory approach that liberates us from a world of path-dependent historical progression to one where desire makes change possible. His aim was to 'find the conditions under which something new is produced' within itself: Creative transformation [9]. To do this, Deleuze uses biological concepts to describe competing systems: A rigid arborescent system - 'a tree-like, rule based, linear structure' [31] and the more organic, non-linear, dynamic and networked structure of the rhizome. To think rhizomically is to reveal the multiple ways possible to assemble thoughts and actions in immanent, always-incomplete processes of change and innovation, or becoming [33]; enabling both creativity and emergence [34]. This fits with situated or social learning as part of a process of what Tsoukas and Chia described as 'the reweaving of actors' webs of beliefs and habits of action to accommodate new experiences obtained through interactions' [35].

From this point of view, 'the traditional privileging of theoretical, discursive knowledge over practical understanding' [36] and the practical accomplishment of learning requires critical reflective thinking. This links more directly and practically with Cunliffe's suggestion that we might consider teaching as a form of 'relationally responsive learning'. Her starting-point is the realization that 'social reality is not separate from us, but that social realities and ourselves are intimately interwoven as each shapes and is shaped by the other in everyday interactions' [37]. Thus, knowledge arises from relationship and this shared development of knowledge between people can form the basis for an egalitarian and socially embedded pedagogy:

Relationally responsive social constructionism highlights the intersubjective, dialogical and dialectical nature of experience, and consequently has implications for the type of knowledge we seek. I suggest this orientation emphasizes an embedded form of knowing, which is often intuitive, but can be explored through reflexive engagement with ourselves and our surroundings [37].

Cunliffe suggests a continuum of attitudes towards knowledge, which she considers relates to a range from objective to subjective: 'At one end of the continuum, researchers take a subjective cognitive approach, focusing on how reality is objectified through interactive and/or discursive and/or processes of construction and sense-making.' [37] Meaning is determined within social systems, and is 
thus subject to prevailing cultural norms, as well as dominant power structures. In this respect, we can acknowledge that this complicates our ability to understand and make sense of the 'ill-defined, unique, emotive and complex issues we face' [38]. In teaching situations, in order to enable a creative flourishing and a shared knowledge, it is necessary for the pedagogue to be self-reflexive and self-critical and to provide space for students to develop critical thinking skills and to question or critically interpret current management ideology, theory and practice. This, suggests Cunliffe, goes beyond 'a purely intellectual critique' [38] and involves a process Cunliffe later refers to as 'relationally responsive interaction' [37] that is central to a relationally responsive process of knowing and learning, as illustrated in Figure 1.

Figure 1. Relationally responsive learning: an overview. Source: adapted from Cunliffe [37].

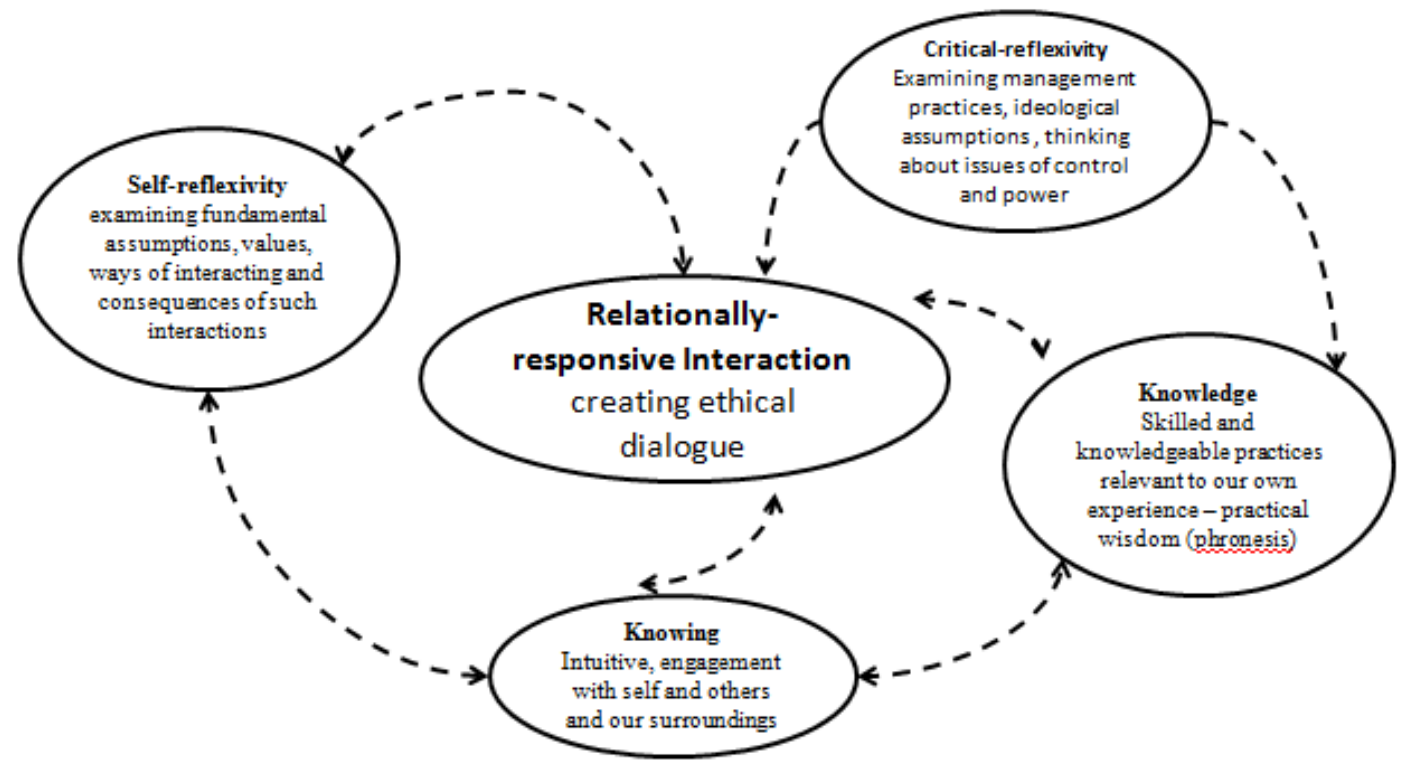

It is within this kind of process, Cunliffe suggests, that we can create meaningful learning experiences for students; facilitating students in creating 'new readings of their experience' ; creating space for action and change [38]; producing actionable knowledge [39]; and providing the scaffolding for learning through life [40]. In the following section we take this understanding one step further by exploring different modes of knowledge.

\section{Examples of Cultural Communication Systems}

The limitation of the view that 'our knowledge comes to us through words' has been exposed in the preceding two sections. None the less, our education system explicitly assumes that this is so. Academic learning takes place through media such as books, papers, essays and lectures. The era of computer-based communication has simply shifted these word-based forms of learning and teaching into an electronic system; it has not changed their fundamental support: The word. In a powerful exposition on the influence of the written word, Abram offers a concern that this reliance on such an abstract and abstracted form of knowing could be the origin of our dislocation from the planet, which is evidenced in the ecological crisis [24]. Somewhat ironically, Abram uses his book to encourage the 
reader to reconnect with the natural world, as well as setting her/him the task of exploring what being part of a culture whose knowledge is not fundamentally literate might be like.

However, we need to make a distinction between the written word, in the context of this discussion, as emblematic of dominant ideologies of teaching and learning that provide us with a recognized and justified 'truth' or objective reality, and the use of language. In doing so, we can also recognize the temporal nature of the written word in how it is interpreted and re-interpreted by the reader, the receiver of the message, in the production of arguments and counter arguments. Furthermore, as Toadvine reminds us, for Merleau-Ponty the style of language (tone, accent, gestural and emotional significance) is linked with nature through the medium of the body and is a "way of vibrating or resonating with its surroundings. Such gestural significations-words, vowels, phenomes-are...so many ways of singing in the world' [41] Through language, as part of narrative knowledge, we construct the creative (rather than literal) stories and accounts of our lives [42]. Both of these latter observations are particularly pertinent to the following examples of communicative systems: The quipu of the former Inca Empire of South America and the Aboriginal songlines.

\subsection{Knotted Cord as Codified Knowledge}

The Inca civilization of Peru lasted for a century and a half before being overrun by the conquistadores. During this time the emperor or Sapa Inca controlled a territory that extended over the territory of modern Peru and also included parts of modern-day Ecuador, Bolivia, Chile and Argentina. The population of the empire was estimated to have been between three and five million. This huge area and population was controlled by an impressive bureaucracy that enforced laws and collected taxes, and yet all this was achieved without the use of the written word. Instead, the Incas communicated in two ways: Their history and culture was shared and maintained orally, through storytelling and discussion; their numerical records were held on small knotted strings known as quipu, which is the Inca word for 'knot'. The knotting system was a decimal accounting system, which involved the use of zero [43].

The information about the state of the economy was transmitted from one end of the empire to the other by means of an impressive system of paved roads, many of which still exist. These were travelled by chasquis, who ran at great speed using these roads and a complex system of rope bridges, the Inca Empire being without the wheel as well as the written word [44]. Use of the quipus themselves was strictly controlled and was only permitted by specially trained quipucamayoqs, who were men of a certain age. For all its apparent exoticism, it becomes apparent that this was actually a communication system of middle-aged male accountants [45].

This is clearly an example of a culture in which the storage and communication of information was understood quite differently from in our culture. While the knotted strings held the information, it was carried physically across large distances, and this was as much a part of the communication system as the quipus themselves. The contrast with our modern internet-based communication, where information can travel from one side of the world to the other almost instantly, appears at first extreme. However, we can also see the structures and linear logic of categories of information codified and stored in a physical system that is not too different from the ledgers, valuation processes and 
hierarchical administrative systems that resonate with more modern methods of cataloguing, carrying out inventories and census checks and tax records [46,47].

Whether this system of string and knots is a communicative device is still undecided. On the one hand it has been suggested that the quipus represent complex, discursive structures - a form of writing; others suggest - specifically those working within 'the European conventions of text', it is no more than a mnemonic device [48]. This raises questions about cultural interpretation of information systems and exploring the meaning and use of quipus is seen as one way of moving knowledge about the Inca civilization out of the frame of Spanish historical recollections [49]. Even so, our interpretation in the context of our discussion here is of a systematized, encoded repository of information as opposed to a dynamic process of knowledge creation.

There is a striking contrast between the quipus and the next communication method we are going to consider: The Aboriginal songlines, a system of communication embedded in the land.

\subsection{Songlines: Pathways, Tracks and Connections between Places}

Aboriginal Creation myths tell of the legendary totemic beings who had wandered over the continent in the Dreamtime, singing out the name of everything that crossed their path-birds, animals, plants, rocks, waterhold-and so singing the world into existence [50].

'Traditional people talk about their inner life as a story of movement between significant places, a journey through landscapes of meaning, conveying the events that occur on that journey, and at the ritual meeting places encountered along the way. Their inner life is lived in their outer life: Land, people, fauna and flora are one, and the dreaming and waka provide a context in which meaning arises.' This description is taken from a paper describing how the Australian and New Zealand Society of Jungian analysts found their experience of the land-based knowing that the songlines represent support in developing their own training practice [51].

In her travels to all corners of the globe undertaken to document the planet's last remaining wildernesses, Jay Griffiths describes the way the indigenous people of the Amazon understand their world through a different sort of songline:

[I]ndigenous people know how to 'think' the forests, know that the paths through this wilderness are songs, the song that each plant has. Song makes a thread of light, a path of the mind; each song tells of one plant's relationship to other plants and not only differentiates one plant from another but distinguishes between the uses of, for example, stem or leaf or root of the same plant. There is practical wisdom here but also psychological wisdom: you find your way and learn how to live unlost, not through the wild forest but within it. The songlines harmonize people with environment. There is no divide [52].

On one level, what we can see with both of these examples are ways of recording information in non-routine, written formats. When presented in a particular order, the songlines provide a map or tracking of places over time and distance with recognizable landmarks and features. However, rather than an objective recording of territory and geography, the Amazonian and Aboriginal songlines 
present a real connection with the land as alive and sacred; more akin to the phenomenological concept of the life world [53].

Unlike the logical system of the quipu, Natale suggests that oral tradition and the Aboriginal worldview present an analogical process of knowledge. She suggests that 'analogical thinking and its symbols, which underlie myths, sacred oral wisdom and spiritual texts..., cannot be reduced to a closed system of signs that can have only one unequivocal meaning and explanation' [54]. Similarly, instead of the seemingly quantitative relationship between the quipu and the quipucamayoqs, Natale describes the qualitative relationship between things in analogical thinking and particularly in relation to language that echoes our earlier discussion in the possibilities for creative reproduction and transformation of specific words as each is 'pronounced, sung, acted or written, renewing not only itself, but also the person who uses it' [54]. In this way, we can start to see a connection to Derrida's concept of performative interpretation as Giroux and Shannon explain:

As a pedagogical practice, performative interpretation suggests that how we understand and come to know ourselves and others cannot be separated from how we represent and imagine ourselves [which reaffirms] the need for people to speak affirmatively and critically out of their own histories, traditions and personal experiences [55].

Further, Giroux and Shannon posit that the bringing together of 'the language of the pedagogical and performative might provide...educators...an opportunity to address the effectiveness of pedagogical practices that are not only interdisciplinary, transgressive, and oppositional but also connected to a wider public project to increase the scope of racial, economic and social justice while expanding and deepening the imperatives of a radical democracy' [55]. This claim provides a springboard to our next section, which looks at examples of community-based sustainability learning and connections with higher education curricula.

\section{Examples of Sustainability Learning as Re-embedding}

The structures and processes of new managerialism and new public management have left their footprint on higher education in terms of internal management practices and increased bureaucracy, but more importantly in the incremental linkages with business and business needs. Curricula are developed around students' ability to demonstrate employability skills, usually with an emphasis on information retrieval and handling; communication and presentation; planning and problem solving; and social development and interaction [56]. We can add to these critical thinking, problem-solving skills, team-based and 'real-life based projects, reflection and problem-based learning, which gives room for basic 'good pedagogy and need not be linked to the workplace to be considered important. There is more to real life than what goes on in the workplace' [57].

This section describes two experiments, which we have been a part of in our home community of Stroud in Gloucestershire, U.K. Stroud is an exemplar sustainable community, where a significant minority of the population are self-consciously modeling radical new approaches to economic and social life - and others are just enjoying the creative atmosphere and stunning countryside of the Cotswold edge. Some examples of sustainability-related innovation in the town include: 
- Stroud Community Agriculture, the country's first co-operative community-supported agriculture business;

- The Space, a community-owned arts centre;

- Stroud Community Woodland, a small piece of woodland that was recently purchased as a community co-operative for artistic and sustainability-related activities [58]

What we are trying to explore, with and among students, is what we mean by sustainable education and learning and how we might build this knowledge into actions in our work and in our lives. To return to Deleuze for a moment, Semetsky comments on Deleuze's own experience and reflection of his own teaching that 'nobody took in everything, but everyone took what they needed or wanted' and that 'understanding, rooted in precepts and affects' is 'embedded in practice' [31]; the experience of the craft. In his exploration of how we might communicate about craft learning, Sennett identifies the writings of John Ruskin as an inspiring example: 'Ruskin's writing is intensely personal; he draws ideas and precepts from his own sensations and experience. The appeal he made, we might formulate today as "get in touch with your body". His prose at its best has an almost hypnotic tactile power, making the reader feel the damp moss on an old stone or see the dust in sunlit streets.' [59]. Ruskin seems to have been able to achieve what we should perhaps aim for in our classroom teaching: To bring his own experience of reality into his verbal communication. But even when raised to this high level, words are still only words. Would it not be better if we were able to share our experiences of nature, and of sustainable living, with our students, so that our emotional and physical responses to them can build the knowledge base that sustainable living required as a joint project in learning?

\subsection{Stroud Communiversity}

Stroud Communiversity is an attempt to create a situation of shared learning in practice, in the projects and businesses that make up a sustainable community in-the-making. The Communiversity was set up in 2008 as a project of Stroud Commonwealth, which is a community brokerage organisation that was a key player in many of the developments listed above. It was the realization that people were coming to visit Stroud to learn about these developments that motivated the establishment of the Communiversity. A group of local people who had either current or previous experience in higher education made links with some of the town's social innovators, who at times felt overwhelmed by the level of interest their creativity had evoked. The decision was made to turn this potential problem into an opportunity by inviting those involved in sustainability-related processes in their own communities to engage in experiential learning in Stroud's various projects and innovative green businesses [60,61].

The first Communiversity, held in August 2008, was launched under the banner, 'Learning is like muck - the more you spread it around, the more growth there is!' and had a number of overlapping themes, including: Living lightly in our environment and work, livelihood and money. The event included visits to a range of local green businesses including Ruskin Mill in nearby Nailsworth, Stroud Community Agriculture, and the U.K.'s only new-build co-housing scheme at Springhill, and the emphasis throughout was on hands-on learning; hence the use of four muddy hands on the top of a spade that is the logo of the Communiversity. While information was shared in the conventional presentation-cum-discussion format, it was one of the guiding principles of the Communiversity that 
this should always be balanced by experiential learning in the projects themselves, and the opportunity to share emotional responses in the group as a whole and in smaller learning groups.

An action learning approach was used [62] to deepen the link between learning and relationship both with the land, the local community, each other. Participants were divided into 'action learning sets' who came with a specific question in their local community which they hoped to enhance and explore during the four-day event. Each day's learning concluded with a quiet session where these groups discussed each other's progress in a carefully managed situation where respectful listening was obligatory and air-time was equally shared. The emphasis during these sessions was on the emotional aspect of learning to balance the practical and intellectual learning that took place in the hands-on and more formal learning sessions.

The feedback from the first Communiversity was universally positive with many people mentioning its impact in terms of inspiration and affirmation when they returned to their own home communities, where sustainability might not be as well developed as it is in Stroud. This, after all, is the role of a sustainability exemplar. A typical comment was 'it has been a great privilage to attend this course-inspiring, thought provoking and brilliant. I think the format is great. I really hope I can start to work with the ideas and put them into practice to help make a difference.' Another participant appreciated the action learning approach: 'Loved the action learning, at end of day to reflect.' Although several of the participants suggested the need to publish the outcomes of the event, this did not happen due to time pressures on the part of the organizers. This paper has another objective, but has allowed some opportunity to reflect on the value of this experiential learning approach in practice.

\subsection{Walking the Land}

Walking the Land provides an even better example of a creative response to the dis-embedding of people from their landscape. It was founded in 2004 by three local artists in Stroud, Gloucestershire who 'share a passion for the landscape, using artworks to bring landscape and environmental issues to a wider public audience. As painters, sculptors, photographers, videographers, curators and educators, we produce work which refers to specific places, localities and environments. [63] Walking the Land is engaged in a range of activities to encourage local people back into their countryside, where a whole range of interesting activities emerge. There are regular First Friday Walks, where once a month a group is guided around a local route and encouraged to document it in drawing or photography. Specialist art walks can be arranged specifically, or focus on a particular aspect of the local landscape, as in the summer 2010 River Severn ArtWalk series or the one-off events Over the Edge (starting out from the village of that name) and Mills and Yew trees involving a ramble around the history and landmarks of the picturesque Painswick village.

The activities are based in Gloucestershire and make links with other local community groups and projects including: Stroud's ambitiously titled Global Bee Project, the Stroud Festival of Nature, and the annual open studios events. The latter offer a particular opportunity to link local artists to the culture and history of the landscape, as in the Site 07 event Racking Fields where visitors to the installation artwork were invited to 'Help recreate the lines of color in the landscape by wearing a red top to add to the spectacle during this journey around Rodborough'. The Stroud scarlet cloth that made the town's fortune was traditionally dried in the surrounding fields, lending them a colorful appearance 
which became a temporary part of the landscape. During the second Communiversity in 2009 Walking the Land co-organised one of the days: An experiential walk in the Slad Valley, home of author Laurie Lee.

The Walking the Land experience is a rare example of that word being used appropriately. The direction from the organizers is deliberately low-key, although they take responsibility for planning the walk and making sure that people do not lose their way, thus freeing the participants to enjoy nature with all their senses. Although a notebook and pencil are encouraged, it is quite permissible to spend the several hours of the walk simply watching, listening and communing with the local environment, and some activities - such as the slow, meditative walk or the walk with eyes closed - are designed specifically to encourage passive experience rather than interaction. Overall, Walking the Land represents an example of how a whole community can deepen its community bonds and learn a new reality in relationship with nature.

\section{Sustainability in Practice: From Knowledge to Action}

Just as the irony of Abram using his book to exhort his readers to make direct connections with the natural world is not lost on us, so we acknowledge the paradox of communicating a message about re-embedding through a peer-review paper, perhaps the apex of a rationalist communication system, a paradox perhaps best symbolized by the sustainability pedagogue typing her paper into a computer whose screen-saver of a beautiful natural scene is the closest she will come to a direct experience of nature during the working day. Beyond irony, such a double standard may express itself to students as hypocrisy, undermining the genuine quality of relationship that a reflexive pedagogue needs to demonstrate. In short, if our argument that teaching sustainability requires a shared experience of wild nature carries conviction, then we will all have to find ourselves venturing out beyond the confines of the normal pedagogical setting, perhaps following examples similar to those discussed in the previous section.

As the experimental nature of the examples from Stroud make clear, we have made considerably more progress with the theory of re-embedding than with the practice. It is also notable that both events are currently outside the formal educational sector, although the authors are striving to bring similar experiences to their business students in a conventional higher educational setting. Since our approach to pedagogy is premised upon the understanding that it is a permanent work in progress, subject to constant refinement and revision by both 'teacher' and 'taught', formal conclusions seem inappropriate. What we have learned during our explorations into experiential learning in the field of sustainability is that 'You need to imagine first and foremost what it's like to be somewhere else in order to do the sorts of things people do there' [59]. If we are to instantiate the sustainable futures we theorize and dream about then we need to find places - perhaps close-at-hand, perhaps distant in time and/or space-where people have enjoyed lifestyles that prefigure these future lifeworlds. Visiting them requires an imaginative step which can be difficult in a conventional classroom setting and is facilitated by learning in situ, at least when inspirational examples are available. As such it may be that learning in practice is not only more constructive but may be essential for students (and their teachers) to undergo the change that is necessary for them to understand what sustainability means. 
What scope is there for breaking the boundaries of the business curriculum in terms of pedagogy as well as content? In our search for innovative practice, we have found some inspiration in third level education outside the mainstream higher education community. One example is the partnership between Schumacher College and the University of Plymouth [64] to provide a master's of arts degree in Economics for Transition. Schumacher College bases all their teaching in pedagogy of transformational learning and a 'holistic approach to learning, research and science' [65]. The emphasis is very much on engaged learning and students are encouraged to spend time in the College's beautiful grounds and the surrounding countryside to deepen the learning experience. The linking of this approach to practice with the more formal requirements of the Plymouth Masters program offers an interesting opportunity to explore the potential for sustainability education as re-embedding.

In our own university we have introduced a new sustainability pathway through the standard Bachelor of Arts degree in Business and Management, called Managing the Transition, which begins to include some re-embedded teaching practice. A compulsory module in the second year is called 'Sustainability in Practice' and is to be taught partly 'in the field'. The course is to begin with several weeks of preparatory work, to ensure that students have a theoretical framework and an expectation about what sustainability might look like. They will then spend a week in Stroud, as an example of an exemplar sustainability community. This time will be spent visiting sustainability-related enterprises and experiencing the local environment, supported by members of Stroud Communiversity and Walking the Land.

This partnership between a higher education institution and a community education group offers opportunities for shared learning and the building of a community of practice. Potential future partners for the Sustainability in Practice module or the third-year field trip include the Centre for Alternative Technology, Machynlleth [66]; Schumacher College in Dartington, Devon [65]; and the Lammas Ecovillage in Pembrokeshire [67]. While this approach to pedagogy may seem fairly mainstream to sustainability practitioners it is a very long way from the conventional teaching approach used in the majority of management schools.

So the dis-embedding and abstraction that our teaching methods seek to overcome has a long pedigree and we should not be too demoralized if our progress appears slower than we would wish, in spite of our sense of the urgent need to address the environmental crisis. Our conviction is that teaching sustainability requires that, before we step into the classroom with handouts and memory-sticks, we should first examine our relationship with our subject-matter, that is to say our students and the world we share. This self-exploration might deepen our understanding of why the subject matters, as well as our commitment to sharing a sustainability outlook with the future generations.

\section{References and Notes}

1. Giroux, H.A. Critical pedagogy and the postmodern/modern divide: Towards a pedagogy of democratization. Teach. Educ. Q. 2004, Winter, 31-47; Available online: http://www.teqjournal.org/backvols/2004/31_1/giroux.pmd.pdf (accessed on 27 September 2010).

2. Lawlor, L. Essence and language: The rupture in Merleau-Ponty's philosophy. Stud. Phaenomenol. III 2003, 3-4, 155-162. 
3. Lawlor, L. Thinking through French Philosophy: The Question of Being; Indiana University Press: Bloomington, IN, USA, 2003.

4. Lawlor, L. The end of phenomenology: Expression in Deleuze and Merleau-Ponty. Cont. Philos. Rev. 1998, 31, 15-34.

5. Somers-Hall, H. Deleuze and Merleau-Ponty: Aesthetics of difference. Presented at The 29th International Merleau-Ponty Conference, Allentown, PA, USA, September 2004; Available online: http://www2.warwick.ac.uk/fac/soc/philosophy/people/alumni/henry-somershall/deleuze_and_merleau-ponty_-_aesthetics_of_difference_-_henry_somers-hall.pdf (accessed on 1 October 2010).

6. Manley, J. From cause and effect to effectual causes: Can we talk of a philosophical background to psycho-social studies? J. Psycho-Soc. Stud. 2010, 4, 1-23.

7. The development of these arguments is beyond the scope of this paper although we acknowledge the relevance of articulating the dichotomies that exist and the available literature that address some of these issues. For example, Manley talks about organic relationships between ourselves and the environment, and Carolan discusses the distinction between episteme (science) and techne (art or skill). In addition, McGilchrist usefully argues for an appreciation of the synergy between right and left brain activity in order to decentralise the dominance of left brain rational and logical exposition of thought and reason and to give room to emotion and connectivity between mind and matter. Equally, Berman speaks of 'participating consciousness' - a wonderfully descriptive phrase which summons up connectivity and embeddedness and involved merger or identification with one's surroundings. See: McGilchrist, I. The Master and his Emissary: The Divided Brain and the Making of the Western World; Yale University Press: London, UK, 2009; and Berman, M. The Re-enchantment of the World; Cornell University Press: New York, NY, USA, 1981.

8. Morris, D. What is living and what is non-living in Merleau-Ponty's philosophy of movement and expression. Chiasmi Int. 2006, 7, 225-239.

9. Deleuze, G.; Parnet, C. Dialogues; Tomlinson, H., Habberjam, B, Trans.; Athlone Press: London, UK, 1987.

10. Merleau-Ponty, M. Phenomenology of Perception; Williams, F., Rev. and Trans.; Humanities Press: New York, NY, USA, 2002.

11. Fischman, G.E.; McLaren, P. Rethinking critical pedagogy and the Gramscian and Freirean legacies: From organic to committed intellectuals or critical pedagogy, commitment, and praxis. Cult. Studs. Crit. Methodol. 2005, 5, 425-447.

12. Revans, R.W. ABC of Action Learning; Lemos and Crane: London, UK, 1998.

13. Revans, R.W. What is Action Learning? J. Manage. Dev. 1993, 1, 64-75.

14. Schön, D. The Reflective Practitioner; Basic Books: New York, NY, USA, 1983.

15. Czarniawaska, B. Is it possible to be a constructionist consultant? Manage. Learn. 2001, 32, 253-266.

16. Boland cited in McAuley, J. Hermeneutic Understanding. In Essential Guide to Qualitative Methods in Organisational Research; Cassell, C., Symon, C., Eds.; Sage: London, UK, 2004.

17. Lave, J.; Wenger, E. Situated Learning: Legitimate Peripheral Participation; Cambridge University Press: Cambridge, UK, 1999. 
18. Gergen, K.J. Social construction and pedagogical practice. Available online: http://www.swarthmore.edu/Documents/faculty/gergen/Social_Construction_and_Pedagogical_Pr actice.pdf; (accessed on 10 July 2009).

19. Feyerabend, P.K. Knowledge, Science and Relativism: Philosophical Papers; Preston, J., Ed., Cambridge University Press: Cambridge, UK, 1999; Volume 3, p. 187.

20. Stock, R. The clash between economics and ecology: Frames and schemas. Int. J. Green Econ. 2009, 3, 285-296.

21. Barnhardt, R. Indigenous knowledge systems and Alaska native ways of knowing. Anthropol. Educ. Q. 2005, 36, 8-23.

22. Ruwhiu, D.; Cone, M. Advancing a pragmatist epistemology in organisational research. Qual. Res. Organ. Manag. Int. J. 2010, 5, 108-126.

23. Bluehorse Skelton, J. Sustainability through Native American Eyes: Dinner Address to 'Cultivating a Sustainable Agricultural Workplace Conference; University of Washington: Seattle, WA, USA, 2004; Available online: http://depts.washington.edu/pnash/conf04/4_Presentations/ 17_BlueHorse_Skelton_Native.pdf (accessed on 1 October 2010).

24. Abram, D. The Spell of the Sensuous; Vintage: New York, NY, USA, 1996.

25. Whipps, J. Pragmatist Feminism. In The Stanford Encyclopaedia of Philosophy; Zalta, E.N, Ed.; 2004. Available online: http://plato.stanford.edu/archives/fall2004/entries/femapproachpragmatism (accessed on 2 June 2005).

26. Brook, I. Can Merleau-Ponty's notion of 'flesh' inform or even transform environmental thinking. Environ. Value. 2005, 14, 353-362.

27. Langer, M. Neitzche, Heidegger and Merleau-Ponty - Some of their contributions and limitations for "Environmentalism". In Eco-phenomenology: Back to the Earth Itself; Brown, C.S., Toadvine, C., Eds.; State University of New York: Albany, NY, USA, 2003.

28. Carman, T. Review of Merleau-Ponty's Nature, Notre Dame Philosophical Reviews; University of Notre Dame: Notre Dame, IN, USA, 2004. Available online: http://ndpr.nd.edu/ review.cfm?id=1440 (accessed on 7 September 2010).

29. Carolan, M.S. An ecological politics of everyday life: Placing flesh on Whitehead's process philosophy in search of "Green" possibilities. Worldviews 2008, 12, 51-73.

30. Plumwood, V. Feminism and the Mastery of Nature; Routledge: London, UK, 1994.

31. Semetsky, I. Not by breadth alone: Imagining a self-organised classroom. Complicit. Int. J. Complex. Educ. 2005, 2, 19-36.

32. Scott Cato, M.; Hillier, J. How could we study climate-related social innovation? Applying Deleuzean philosophy to the transition towns. Environ. Polit. 2010, 19, 869-887.

33. Colman, F. Rhizome. In The Deleuze Dictionary; Parr, A., Ed.; Edinburgh University Press: Edinburgh, UK, 2005; pp. 231-233.

34. Deleuze, G. Cinema 2: The Time-Image; Tomlinson, H., Galeta, R., Trans.; University of Minnesota Press: Minneapolis, MN, USA, 1989.

35. Tsoukas, H.; Chia, R. On organizational becoming: Rethinking organizational change. Organ. Sci. 2002, 13, 567-582. 
36. Kokkalis, P.; Zundel, M. A penny for your thoughts: Assembling the interplay of action and reflection from a Heideggarian perspective. Presented at The First International Symposium on Process organization Studies, Pissouri, Cyprus, June, 2009.

37. Cunliffe, A.L. Orientations to social constructionism: Relationally responsive social constructionism and its implications for knowledge and learning. Manage. Learn. 2008, 39, 123-139.

38. Cunliffe, A.L. Reflexive dialogical practice in management learning. Manage. Learn. 2002, 33, 35-61.

39. Antonacopoulou, E. Impact and scholarship: Unlearning and practising to co-create actionable knowledge. Manage. Learn. 2009, 40, 421-430.

40. Nicolaides, A.; Yorks, L. Complexity and philosophy-An epistemology of learning through. E:CO 2008, 10, 50-61.

41. Toadvine, T. Singing the world in a new key: Merleau-Ponty and the ontology of sense. Janus Head 2004, 7, 273-283.

42. Cunliffe, A.L.; Luhman, J.T.; Boje, D.M. Narrative temporality: Implications for organisational research. Organiz. Stud. 2004, 25, 261-286.

43. Christensen, A. The Incan Quipus. Synthese 2002, 133,159-172.

44. Espinosa, R.M. The Great Inca route: A living experience. Mus. Int. 2004, 56, 102-110.

45. Urton, G.; Brezine, C.J. Khipu Accounting in Ancient Peru. Science 2005, 309, 1065-1067.

46. Salomon, F. The Cord Keepers: Khipus and Cultural Life in a Peruvian Village; Duke University Press: Durham, NC, USA, 2004.

47. Mann, C.C. Unravelling Khipu's Secrets. Science 2005, 309, 1008-1009.

48. Buffalo, N.Y. University of Buffalo, Professor works to unravel mysteries of Khipu: Colored, knotted strings used by the Ancient Incas. Science Daily, 5 January 2004. Available online: http://www.sciencedaily.com/releases/2004/01/040105071006.htm (accessed on 1 October 2010).

49. Potier, B. String theorist: Anthropologist Gary Urton untangles the mystery of Inkan Khipus. Harvard University Gazatte, May, 2003. Available online: http://www.news.harvard.edu/ gazette/2003/05.22/03-urton.html (accessed on 1 October 2010).

50. Chatwin, B. The Songlines; Penguin Books: London, UK, 1988; p. 2.

51. Caulfield, M. Part One: A new rhythm for the Australia and New Zealand Society of Jungian Analysts. J. Anal. Psychol. 2008, 53, 62-71.

52. Griffiths, J. Wild: An Elemental Journey; Hamish Hamilton: London, UK, 2009.

53. Huggan, G. Maps, dreams and the presentation of ethnographic narrative: Hugh Brody's "Maps and Dreams" and Bruce Chatwin's "The Songlines". ARIEL-Rev. Int. Engl. 1991, 22, 57- 69.

54. Natale, A.R. Bruce Chatwin and the aboriginal story "Murgah Muggui": Threading songlines and webs of lives. J. Eur. Assoc. Stud. Aust. 2009, 1, 108-115.

55. Giroux, H.A.; Shannon, P. Education and Cultural Studies: Towards a Performative Practice; Routledge: London, UK, 1997; p. 7.

56. Steven, C.; Fallows, S. Enhancing employability skills within higher education: Impact on teaching, learning and assessment. Presented at the Higher Education Close Up International Conference, Preston, UK, 6-8 July 1998. Available online: http://www.leeds.ac.uk/educol/ documents/000000700.htm (accessed on 1 October 2010). 
57. Noble, D.D. Let Them Eat Skills. In Education and Cultural Studies: Towards a Performative Practice, Giroux, H.A., Shannon, P., Eds.; Routledge: London, UK, 1997; p. 208.

58. Large, M. Common Wealth: For a Free, Equal, Mutual and Sustainable Society; Hawthorn Press: Stroud, UK, 2010.

59. Sennett, R. The Craftsman; Penguin: Harmondsworth, UK, 2008; pp. 109, 188.

60. Newton, J.; Franklin, A.; Middleton, J.; Marsden, T. Understanding the Role of Skills, Learning and Knowledge for Sustainable Communities; Working Paper No. 51; The Centre for Business Relationships, Accountability Sustainability and Society (BRASS): Cardiff, UK, 2009. Available online: http://www.brass.cf.ac.uk/uploads/WP51Sustainable_Communities.pdf (accessed on 1 October 2010).

61. Stroud Communiversity, 2008. Available online: http://www.stroudcommonwealth.org.uk/ documents/stroud_communiversity_review.pdf (accessed on 1 October, 2010).

62. Rehm, R.; Cebula, N.; Large, M.; Ryan, F. Futures that Work: Using Search Conferences to Revitalize Companies, Communities and Organizations; Hawthorn Press: Stroud, UK, 2002.

63. Scott Cato, M.'s personal communication with the organizers, and the Walking the Land website. http://www.walkingtheland.org.uk (accessed on 1 October 2010).

64. MA in Economics for Transition; Schumacher College: Devon, UK, 2010. Available online: http://www.schumachercollege.org.uk/courses/ma-in-economics-for-transition (accessed on 2 November 2010).

65. About the College; Schumacher College: Devon, UK, 2010. Available online: http://www.schumachercollege.org.uk (accessed on 2 November 2010).

66. What Do We Do? Centre for Alternative Technology: Machynlleth, UK, 2010. Available online: http://www.cat.org.uk (accessed on 2 November 2010).

67. The Eco Village: Pioneering "Low-Impact Developments"; Lammas: Pembroke, UK, 2010. Available online: http://www.lammas.org.uk (accessed on 2 November 2010).

(C) 2010 by the authors; licensee MDPI, Basel, Switzerland. This article is an open access article distributed under the terms and conditions of the Creative Commons Attribution license (http://creativecommons.org/licenses/by/3.0/). 